\title{
Age-Related Inflammation: the Contribution of Different Organs, Tissues and Systems. How to Face it for Therapeutic Approaches
}

\author{
E. Cevenini ${ }^{1}$, C. Caruso ${ }^{2}$, G. Candore ${ }^{2}$, M. Capri ${ }^{1}$, D. Nuzzo $^{3}$, G. Duro ${ }^{3}$, C. Rizzo ${ }^{2}$, G. Colonna-Romano ${ }^{2}$, D. \\ Lio $^{2}$, D. Di Carlo ${ }^{2}$, M. G. Palmas ${ }^{1}$, M. Scurti ${ }^{1}$, E. Pini ${ }^{1}$, C. Franceschi ${ }^{1}$ and S. Vasto ${ }^{2, *}$
}

${ }^{I}$ Department of Experimental Pathology and C.I.G. - Interdepartmental Center "L. Galvani" for Integrated Studies on Bioinformatics, Biophysics, and Biocomplexity, University of Bologna; ${ }^{2}$ Immunosenescence Unit, Department of Pathobiology and Biomedical Methodologies, University of Palermo; ${ }^{3}$ IBIM, National Research Council, Palermo, Italy

\begin{abstract}
A typical feature of ageing is a chronic, low-grade inflammation characterized by a general increase in the production of proinflammatory cytokines and inflammatory markers ("inflamm-ageing"). This status may slowly damage one or several organs, especially when unfavorable genetic polymorphisms and epigenetic alterations are concomitant, leading to an increased risk of frailty together with the onset of age-related chronic diseases. The contribution of different tissues (adipose tissue, muscle), organs (brain, liver), immune system and ecosystems (gut microbiota) to age-related inflammation ("inflamm-ageing") will be discussed in this review in the context of its onset/progression leading to site-restricted and systemic effects. Moreover, some of the possible strategies and therapies to counteract the different sources of molecular mediators which lead to the age-related inflammatory phenotype will be presented.
\end{abstract}

Keywords: Ageing, age-related diseases, immunosenescence, inflammation.

\section{INFLAMMATION AND AGEING}

Ageing, an inexorable intrinsic process that affects all cells, tissues, organs and individuals, is a post-maturational process that, due to a diminished homeostasis and increased organism frailty, causes a reduction of the response to environmental stimuli and, in general, is associated to an increased predisposition to illness and death [1].

A typical feature of ageing process is the development of a chronic, low grade, inflammatory status referred to as "inflammageing" [2-4] and this condition has emerged as critical in the onset of sarcopenia, frailty and the pathogenesis of several age-related chronic diseases, such as Parkinson's and Alzheimer's disease (AD), atherosclerosis and type 2 diabetes [5-9]. All these diseases (and disabilities) appear to share the same process of inflammation, leading to the concept of an age-related diseasome [10]. So, genes and epigenetic factors involved in the regulatory pattern of inflammation should play a role in human ageing, in fact many functional cytokine polymorphisms were found as associated to unsuccessful ageing or longevity [11]. Furthermore high serological levels of pro-inflammatory mediators like cytokines and c reactive protein (CRP) seem to be the marker of unsuccessful ageing, as recently reviewed $[1,5]$.

Actually, inflammation is a systemic physiological process fundamental for survival, which involves a variety of cells and organs but its persistence over years/decades and deregulation favour the onset of several age-related diseases as previously stated. On the whole, the possibility to counteract these pathologies represents one of the most important biomedical and public health challenges [12]. Despite its enormous complexity, involving combinations of genetic, epigenetic, environmental and stochastic factors, a few basic molecular mechanisms appear to underpin the ageing process, involving a set of highly conserved mechanisms [13]. One of these seems likely to be inflammation, as previously stated. In particular, a variety of tissues (adipose tissue, muscle), organs (brain, liver), systems (immune system) and ecosystems (gut

"Address correspondence to this author at the Immunosenescence Unit, Department of Pathobiology and Biomedical Methodologies, University of Palermo, Italy; Corso Tukory, 211 - 90134 Palermo, Italy;

Tel: +390916553288; Fax: +390916553230; E-mail: s.vasto@unipa.it microbiota) of the body contribute in a different manner to inflamm-ageing onset/progression with specific site or organsrestricted effects and systemic effects, as shown in Fig. (1) and discussed later.

This review will deal with the major findings regarding the sources of the inflammatory stimuli underpinning and sustaining age-related inflammation together with the possible strategies to counteract the inflammatory status. In this context the role of senescent-associated secretory phenotype will be not deeply considered since it is beyond the scope of the review.

\section{POSSIBLE CONTRIBUTORS TO THE INFLAMMATORY PHENOTYPE THAT OCCURS WITH AGE}

\subsection{Immune System}

During ageing the immune systems is progressively remodelled with changes in a dynamic process which mainly depends on the evolutionarily unpredicted, chronic lifelong persisting antigenic load (immunosenescence) [14]. Indeed, there is a link between individual exposure to past infection, levels of chronic inflammation and increased risk of heart attack, stroke, AD and cancer. Notably, CRP levels are correlated with the number of seropositivities to common pathogens, suggestive of infection history $[5,9,15,16]$. However, an age-related increase in the production of inflammatory compounds occurs in the immune system and one of the leading causes of death in very elderly are persistent infections, including Epstein Barr virus and cytomegalovirus (CMV) [17]. CMV is amongst the largest and most complex of known viruses and chronic CMV infection actually plays a major role in immunosenescence, indeed the immune system in old people is full of megaclones specific for CMV epitopes [18]. Healthy seropositive subjects aged 19-55 years are able to maintain CMV under control by broadly targeting the overall CMV proteome with about $10 \%$ of both $\mathrm{CD}^{+}$and $\mathrm{CD} 8^{+}$peripheral $\mathrm{T}$ cells which produce intracellular interferon (IFN)- $\gamma$ [19]; however a much larger percentage (20$50 \%$ ) of $\mathrm{T}$ cells are involved in protecting the elderly from CMV endogenous reactivation. Such an enormous and stable burden of effector $\mathrm{CD}^{+}$and $\mathrm{CD}^{+} \mathrm{T}$ cells producing IFN- $\gamma$ and tumor necrosis factor (TNF)- $\alpha$ may contribute to inflamm-ageing [20].

This evidence indicates that the evolutionarily "negotiated" balance between viral mechanisms of pathogenesis, persistence and 
immune evasion and the host cellular immune response may be profoundly altered in very old people; our immune system is quite efficient in coping with acute infections in young people, but the same system is not particularly efficient in responding to chronic stimuli, particularly when it occurs in old subjects. Furthermore, chronic CMV infection is associated with frailty, a state with increased morbidity and mortality in older adults, and inflammation status, measured in terms of interleukin (IL)-6 levels, enhances this effect [21].

The most recent studies on immunosenescence have been devoted to the identification of an Immune Risk Phenotype (IRP), informative and predictive for morbidity and mortality in the elderly $[22,23]$. It is characterized by a CD4/CD8 of $<1$ owing to an accumulation of late stage differentiated CD8 cells many of which are specific for CMV antigens. CMV infection and high plasma level of pro-inflammatory cytokine (such as IL-6) are biomarkers of immunosenescence affecting inexorably human immunity [24].

In addition genetics impacts on immune system response during ageing. It is demonstrated that functional cytokine gene polymorphisms influence the cytokine production, playing a role as susceptibility or resistance factors against immune-mediated and infectious disease. That is the case, amongst other, of genetic variations in the $-308 \mathrm{~A} / \mathrm{G}$ locus for TNF- $\alpha$ and the $-308 \mathrm{~A}$ allele which may be one of the susceptibility factor for infectious diseases in old persons, particularly considering its association with the increased release of pro-inflammatory cytokines and with the reduction of zinc release and methallothionin, fundamental for the inflammatory response [25]. Most generally, as previously conceptualised [2], specific genetic variants associated to a persistent proinflammatory status can favour the onset of age-related diseases.

\subsection{Gut Microbiota}

Current research on human gut microbiota states that the size of this ecosystem, consisting of about 100 trillions of microbial cells and an "extended genome" of millions of microbial genes (the microbiome), is around 10 times greater than the total number of somatic and germ line cells. Because this complex symbiosis influences host metabolism, physiology, and gene expression, it has been proposed that humans are complex biologic "superorganisms." [26-28].

Gut microbiota and gastrointestinal-associated immune system coexist in a balanced microenvironment where cytokines and lymphocytes have to cope with the antigenic load, in order to control the enormous variety of bacterial species within the intestinal microflora. This physiological condition where bacteria and their products have to be tightly surveyed by immune cells may have a profound impact on human health, influencing the nutritional, physiological and immunological status of the host $[29,30]$. Specifically, the production of potentially toxic compounds (xenobiotics) either ingested with the diet or locally produced as a consequence of the microbial metabolism may affect host health condition [31]. Indeed, gut microbiota affects various characteristics of the host (fat storage, obesity) $[28,32,33]$ and intestinal disorders such as the irritable bowel syndrome, inflammatory bowel disease and colon cancer [34-36].

Furthermore, a profound derangement of intestinal microflora is present in frail elderly people and may contribute to the age-related inflammatory status. This derangement of the intestinal microflora likely represents an important source of continuous antigenic stimulation and contributes to immunosenescence. Therefore, on the basis of its potential importance as a major source of chronic stimuli (immunological/inflammatory/toxic/metabolic) to other organs and systems, such as immune system and liver, we can surmise that age-related changes of composition and function of the gut microbiota may play a major role in the development and maintenance of inflamm-ageing. At present, a study on gut microbiota composition shows that three main modifications occur in faecal microbiota from old frail subjects: a 26-fold reduction in the number of lactobacilli (which stimulate immune functions and help the nutrient absorption), a 3-fold reduction in the number of bacteriodes (which digest polysaccarides, some species are opportunist pathogens) and a 7-fold increase in the number of enterobacteriacee (potentially pathogens) [37]. Differences in faecal microbiota were also found in a study on people of different countries and ages, including aged and long-lived people [38].

Therefore, the elucidation of the intestinal microbiome is likely to underpin future disease prevention strategies, personalized health care regimens, and the development of novel therapeutic interventions that takes into account the complex genetic scenario including genes embedded in human affiliated microbiome, accounting alone for $>100$ times as many genes as those of the human genome $[39,40]$.

\subsection{Adipose Tissue}

Recent studies on adipogenesis show the haematopoietic origin of adipocytes [41] which can directly produce a series of peptides named adipokines.

It has been demonstrated that the adipose tissue increases quantitatively with age throughout the body, including organs such as liver and bone marrow, and it actively contributes to the establishment of the chronic low-grade systemic inflammation, by producing high level of adipokines [42]. This augmented body fat is characterized by increased visceral adiposity and it occurs despite the decreased subcutaneous fat and progressive sarcopenia typical of ageing. In particular, visceral adiposity, characteristic of obesity, has been associated with greater risks for age-related diseases, including insulin resistance, type 2 diabetes, metabolic syndrome, fatty liver disease, atherosclerosis, degenerative disorders including dementia, airway disease and some cancers [43].

Obese adipose tissue is characterized by progressive infiltration of macrophages as obesity develops and these macrophages are an important source of inflammation in this tissue [44]. The infiltration of macrophage can occur through different mechanisms. In obesity, adipocytes begin to secrete low levels of TNF- $\alpha$, which can stimulate preadipocytes to produce monocyte chemoattractant protein-1 (MCP)-1 which attracts macrophages. Similarly, endothelial cells also secrete MCP-1 in response to cytokines. Thus, either preadipocytes or endothelial cells could be responsible for attracting macrophages to adipose tissue. Increased secretion of leptin (and/or decreased production of adiponectin) by adipocytes may also contribute to macrophage accumulation by stimulating transport of macrophages to adipose tissue and promoting adhesion of macrophages to endothelial cells. This condition appears to be very similar to that seen in atherosclerosis [45].

Whatever the initial stimulus to recruit macrophages into adipose tissue is, these cells along with adipocytes and other cell types could perpetuate a vicious cycle of their recruitment, the production of inflammatory cytokines, and the impairment of adipocyte function [46]. Furthermore, obesity is tightly correlated to insulin resistance by the adipose tissue production of proinflammatory TNF- $\alpha$, that is overexpressed in obese animals and humans [47]. The activation of proinflammatory pathways after exposure to TNF- $\alpha$ induces a state of insulin resistance in terms of glucose uptake in adipocytes that impair insulin signalling at the level of the insulin receptor substrate proteins, as recently reviewed $[48,49]$. This results are further confirmed in obese mice lacking TNF- $\alpha$ or its receptor that show protection against developing insulin resistance [50].

Despite the great amount of data showing the contribution of adipose tissue to inflammation, it has not yet clarified if it is active also in normal weight individuals and if the visceral adipose tissue 
is a source of inflammation in any case or only under specific condition.

\subsection{Muscle}

In the elderly, muscles become atrophic (loss in muscle mass) and weaker (loss in muscle force), more susceptible to damage and consequently the regeneration and recover occur more slowly than was the case in youth. This condition leads to sarcopenia, the agerelated loss of skeletal muscle mass, which can start as early as 30 years of age. It can result in a loss of about $30-50 \%$ of the muscle mass by the age of 80 years, in a progressive decline of movement speed and reaction times [51]. Due to the ongoing ageing of Western populations the prevalence of sarcopenia is expected to dramatically increase, thus each strategy to counteract this agerelated muscle loss is strongly pursued.

The biological mechanisms responsible for sarcopenia are complex. In elderly, there is a decline in a variety of neural, hormonal, and environmental trophic signals to muscle. The most important endogenous cause may be the irreversible age-related loss of $\alpha$-motor units in the central nervous system, on the other hand the most important environmental cause of sarcopenia is the lack of physical activity with its beneficial effects in terms of antiinflammatory regulators [52].

Serum levels of testosterone, estrogens and androgens decline with age and they are known to be involved in the decrease of muscle mass [53]. All these aspects can modify downstream cell signaling, decreased protein synthesis and a decreased ability of the muscle stem cells (the satellite cells) to repair and maintain muscle mass [54]. Among the various factors involved in the aetiology of muscle weakness and sarcopenia, it seems clear that chronic inflammation also plays a major role [2,55]. In fact there is increasing evidence that a raise of inflammatory cytokines, possibly in combination with reduced growth factor levels, contributes to the development of sarcopenia and age-related physical decline [56,57]. Furthermore epidemiological studies have shown that there is a correlation between high levels of inflammatory markers (such as IL-6 and CRP), low levels of insulin growth factor (IGF)-1, high levels of oxidative stress, decreased mitochondrial function and muscle weakness [58-60]. Alongside, a correlation between hormonal reduction and inflammation is present, since estrogen decline seems to increase the levels of pro-inflammatory cytokines such as IL-6 and TNF- $\alpha$ [61].

Epidemiological studies have reported that IL-6 is strongly associated with functional disability and loss of muscle mass but experimental studies have not been able to link IL-6 to sarcopenia $[58,62]$, even if in vitro cellular models showed that IL-6 downregulates IGF-1 and in turn the effect of low IGF-1 levels may stimulate IL-6, suggesting a biological link between IGF-1, IL-6 and estrogen [63]. However, human investigations have shown that inflammation impairs muscle strength in elderly people [64] while IGF-1 and IL-6 plasma levels were synergistically related to disability and mortality in older women [56]. In this context, it is worth noting to outline that the muscle restricted IGF-1 (mIGF-1) plays a fundamental role in muscle growth and remodelling [65]. It has been demonstrated that mIGF-1 transgene accelerates the regenerative process of injured skeletal muscle, modulating the inflammatory response, and limiting fibrosis. At the molecular level, mIGF-1 expression significantly down-regulates pro-inflammatory cytokines, such as TNF- $\alpha$ and IL- $1 \beta$, and modulates the expression of chemokines. In addition, mIGF-1 expression modulates key players of inflammatory response, such as macrophage migration inhibitory factor (MIF), high mobility group protein-1, and transcription factor NF- $\kappa \mathrm{B}$ [65].

However, the situation is much more complex because it is emerging that some cytokines, such as IL-6, appear to have contextspecific pro- or anti- inflammatory effects. To this regard, it has been demonstrated that during and after exercise IL- 6 is produced and released by muscle fibres: IL- 6 stimulates the appearance in the circulation of other anti-inflammatory cytokines such as IL-1ra and IL-10 and inhibits the production of the pro-inflammatory cytokine TNF- $\alpha$ [66].

In addition, IL-6 was introduced as the first myokine, that is produced and released by contracting skeletal muscle fibres, exerting its effects in other organs of the body. Myokines may be involved in mediating beneficial health effects against chronic diseases associated with low-grade inflammation such as diabetes and cardiovascular diseases. In this case IL-6 is an anti-inflammatory signalling molecule, leading to increased lipolysis, increased glucose uptake and decreased inflammatory response [6769].

Therefore in this multifaceted contest, we suggest that there is a trade-off between the inflammatory status that tends to decrease muscle mass and the anti-inflammation factors, that, on the other side, tend to increase muscle mass. It is on this microenvironment that possible strategies could be applied for sustaining more efficient muscle regeneration and repair.

\subsection{Brain}

Normal brain ageing is associated with chronic low-grade inflammation. A growing amount of literature is related to the development of dementia and particularly Alzheimer's Disease (AD). $\mathrm{AD}$ is a heterogeneous and progressive neurodegenerative disease that in Western societies accounts for the majority of clinical senile dementia. Many inflammatory mediators have been detected in regions of the brain of patients with $\mathrm{AD}$ and astrocyte and microglial cells activation has a fundamental role in the inflammatory pathogenesis, as stated by the amyloid cascade/neuroinflammation hypothesis [70]. Astrocytes are responsible for the production of the neurotoxic substances, such as reactive oxygen and nitrogen species, pro-inflammatory cytokines, complement proteins, and other inflammatory mediators that bring important neurodegenerative changes [71]. The microglia activation can be due to local or systemic inflammation. In fact a strong local inflammatory stimulus such as a previous head trauma is a risk factor for $\mathrm{AD}$ and several epidemiological studies clearly show that blood elevations of acute phase proteins, markers of systemic inflammatory stimuli, may be risk factors for cognitive decline and dementia [72-74].

It has been seen that several genetic and environmental factors are involved in $\mathrm{AD}$ onset as recently reviewed [75], thus confirming that the inflammatory status cannot be per se the only "hit" or condition able to force the development of the pathogenesis [2].

However, several data demonstrate that immune-inflammatory parameters are modified in blood lymphocytes obtained from AD patients and stimulated in vitro by amyloid [76]. Data on involvement of the immune system in $\mathrm{AD}$ are controversial and difficult to fully understand. The results obtained in these studies can, on one hand, be the mirror of lymphocytes $\mathrm{T}$ and microglial locally activated in brain AD patients, on the other hand the activation of peripheral lymphocytes might be the result of the systemic activation of immune-inflammation.

\subsection{Liver}

There are very few experimental data on age-dependent changes in human liver, and they are mainly related to its morphological and histological modifications, together with functional decline of mitochondria in hepatocytes [77]. Human liver appears to preserve its function relatively well [78], but the evaluation of the role of the liver in age-related inflammation, its ageing rate are scanty and unsatisfactory [79]. Surprisingly, clinical data indicate that liver grafts from aged donors (also over 90 years) have functionality and graft duration comparable to those achievable with liver grafts from young donors [80]. These clinical and surgery data could be suggest that human liver ageing undergoes a 
negligible age-related changes. On the other side, many factors could influence the biological age of the organ, such as hepatitis, virus infectious, diet, alcohol consumption, regeneration capacity and pro- or anti-inflammatory microenvironment. This last factor is particularly interesting for the purpose of the present review, and it could be due also to the function and activation of Kupffer cells, which account for $80 \%-90 \%$ of the body's resident macrophages [81]. It appears to be maintained or even increased in old age (Kupffer cell numbers: 3-fold; activity: 5-fold) with important implications both for site-restricted inflammatory responses [82].

In addition, the tightly connection between gut microbiota and liver is still poorly understood. There are various alterations of the gastrointestinal tract in liver disease and portal hypertension, which might be less clinically overt than potentially life-threatening features, such as ascites. However, these alterations, for example gut-barrier dysfunction and alterations of gut microbiota, have a great impact on the portal enteropathy, as they both contribute to the systemic inflammation in liver cirrhosis, which is considered a risk factor for infections as well as the development of cachexia [83].

Very recently, the role of the liver towards the cell-mediate immune response has been addressed in mice model and data obtained indicate that liver has the potential to "remember" its lymphoid function [84], thus opening new hypothesis on liver contribution to inflammatory status both at organ and systemic level in a suggestive fashion.

\section{POSSIBLE $A D$ HOC STRATEgIES TO COUNTERACT THE INFLAMMATORY STATUS}

\subsection{Vaccinations}

Because lifelong, acute or chronic exposure to bacteria, viruses, and other pathogens or antigens can induce a progressive increase of the inflammatory status during ageing, any procedure aimed at avoiding immunological extra burden is highly recommended for elderly individuals. First of all, careful attention should be paid to neglected sources of antigenic stimulation, such as chronic, subclinical infections in the oral cavity and the gastrointestinal and urogenital tracts, amongst others, which probably represent a major source of chronic antigenic stimulation. From this point of view, a systematic search for chronic infections, and the setup of safe procedures to eradicate them, would be likely to have a strong, beneficial impact on health status and functional capability, but also on overall survival and life span in the elderly [39].

Another strategy to counteract immunosenescence is to reduce as much as possible the antigenic load represented by common infectious agents such as influenza virus, hepatitis viruses and CMV, amongst others. Strategies of specific vaccination should be applied to prevent, not only morbidity and mortality, but also any additional persistent stimulation of the immune system in the elderly $[85,86]$ However, the antibody response to influenza vaccine in the elderly is considerably lower than in younger adults [87], and the efficacy and effectiveness of vaccine in elderly individuals living in a community seem to have a modest impact in meta-analysis studies [88]. In addition, some published data suggest a correlation between CMV-seropositivity, chronic pro-inflammatory activity, and non-responsiveness to the anti-influenza vaccine. This phenomenon appears to be age independent, even if more pronounced in elderly subjects [89]. Because CMV seems to be one of the main driving force of immunosenescence, and because the number of $\mathrm{CMV}^{+}$subjects increase with age, the possibility of administrating large-scale vaccination against CMV early in life should be envisaged. Indeed, immunization strategies against CMV could be potentially highly protective, as they should avoid the accumulation of terminally differentiated $\mathrm{T}$ cell megaclones. However, anti-CMV adoptive immunotherapies [90,91] are nowadays not satisfactory because they are insufficient to provide a long-lasting resistance to CMV, and further studies are urgently needed for more effective anti-CMV vaccines. Many groups are presently developing new approaches which seem to be more promising than previous procedures [92]. However, any large-scale immunization strategy in the elderly has to face the additional problem of the before mentioned age-related changes in $\mathrm{B}$ and $\mathrm{T}$ cell subsets, which in turn interfere with the effectiveness of vaccination. There is a specific need for the development of an $\mathrm{ad}$ hoc vaccine appropriate for the elderly and their immune status.

A further strategy to improve the immune system in elderly, and so also lowering the pro-inflammatory status, could be the deletion of $\mathrm{T}$ megaclones, which are poorly responding cells that produce inflammatory cytokines and contribute to the IRP [93]. The selective elimination of these megaclones could theoretically be performed by purging techniques [94-97], specifically upgraded with antibodies/tetramer complex, that recognize the different megaclones. However, it is evident that these approaches in humans, especially in elderly individuals, are not easily practicable. On the other hand the emptying of the immunological space, consequent to the removal of the megaclones, in turn could trigger the homeostatic proliferation of the remnant memory $\mathrm{T}$ cell clones, frustrating the attempt to eliminate them $[98,99]$. In addition, naive $\mathrm{T}$ lymphocytes may acquire a phenotype similar to antigenexperienced memory $\mathrm{T}$ cells, but this type of cells are not sufficient to mediate an effective immune response, as recently demonstrated in mouse model [100].

Further investigations have to be addressed towards a personalised therapy such as the genetic screening of subjects more susceptible to acute and/or recurrent infectious diseases (HLA subgroups) and the administration of vaccines constituted only by HLA-restricted immunodominant peptides.

\subsection{Probiotic Treatment}

The derangement of the intestinal microflora that occurs with age seems likely to represent an important source of continuous antigenic stimulation which contributes to immunosenescence. Optimal gut microbiota may play a role as anti-inflammatory agents contributing to late life survival in good health, therefore tools for large-scale monitoring of such age-associated derangement and specific strategies to reconstitute the normal microflora in the elderly are urgently needed and should represent a priority in ageing research. A large body of literature on possible therapeutic manipulation of the normal flora in enteric diseases is available, and experimental treatments with bacterial unmethylated cytosineguanine (CpG)-DNA sequences that have immunostimulatory effects, have been recently published and represent an interesting perspective for future therapies in the enteropathies [101] Data from animal models testing the efficacy of probiotic treatment for inflammatory bowel disease seem to be very promising [102], and recent data obtained in in vitro experiments suggest that Bifidobacterium genomic DNA up-regulates the secretion of antiinflammatory IL-10 by peripheral blood mononuclear cells [103]. Bacteria could also be exploited by genetic engineering in order to deliver anti-inflammatory cytokines or other biologically active molecules to the gut. To this purpose, efficacy tests of these approaches have been done in mice with Lactobacillus lactis engineered to secrete IL-10 or single-chain antibodies for pathogenspecific passive immunity [104].

The propensity of the intestinal immune system to generate tolerance to non-invasive antigens is well known, and this is a formidable challenge for the development of novel orally active vaccines. Oral tolerance is finely tuned because mucosal surfaces also represent a major site of pathogen entry, and the immune system is able to mount an effective response to protect the body from invading microorganisms, while maintaining tolerance to "harmless" antigens. In order to avoid the onset of possible autoimmune phenomena, any procedure aimed to increase immunity at 
the mucosal level should not interfere with physiological mechanisms of tolerance to luminal antigens in the gut, whose alteration may lead to immune-mediated pathology, such as Crohn's disease and ulcerative colitis. In any case, this antiimmunosenescence strategy needs further knowledge of dendritic cells and of their role in oral tolerance. A wide range on dendritic subpopulations is present at the mucosal immune system, some of the lineage and subset being still poorly known $[39,40]$.

\subsection{Non Steroidal Anti-Inflammatory Drugs (NSAIDs)}

The age associated increase in pro-inflammatory cytokines in the elderly, raises the possibility that some pro-inflammatory cytokine blocking antibodies or soluble receptors could also beneficial for elderly. Moreover, there are other less potent well-known inflammation-modulating drugs, such as statins and NSAIDs that have few side effects and can be used with safety even in very old subjects. On the basis of this, it is reasonable to assume that antiinflammatory treatments could be useful to counteract and to reduce the age-dependent inflammatory status, preventing the development of age-related inflammatory diseases. In particular, several epidemiological studies have suggested that long-term treatment with NSAIDs may reduce the risk of developing AD [74]. On the other hand, a recent report based on a longitudinal study of men and women aged 70 years and older with a family history of AD (ADAPT study) showed that use of naproxen or celecoxib did not improve cognitive function. However, several critical issues have been raised concerning the study results, i.e. it has been claimed that the ADAPT study does not indicate that NSAIDs, if taken during adulthood and for an extended period, cannot prevent or delay the onset of dementia [105,106]. On the other hand, it has been seen that statins reduce amyloid-mediated microglia neurotoxicity in vitro independently from cholesterol lowering, providing a rationale for their use in AD. However, contrasting therapeutic results have been obtained, so additional studies are necessary to definitively assess the effects of statins on AD.

Epidemiological studies have shown that prolonged aspirin ingestion reduces the incidence of prostate cancer. This effect might result, at least in part, from Cyclo-oxygenase(COX)-2 inhibition. However, it is possible that the anti-cancer activity of these compounds might also reflect COX-independent effects, since high concentrations of NSAIDs suppress the growth of cells in culture that do not express COX-2 [107].

\subsection{Diet}

It is becoming clearer how food intake and life style can influence life span. If on the one hand protein-malnutrition is cited as the major cause of immunodeficiency worldwide, on the other hand high fat intake is the major cause of metabolic inflammatory disease. So weight control and nutrient analysis can contribute to protect against chronic inflammation and metabolic complications (e.g., visceral obesity, type 2 diabetes and atherosclerosis). High intake of meat and total protein and lower intake of fruit, vegetables are associated with increased risk of inflammatory arthritis whereas a Mediterranean type diet might have a protective role [108]. Fat intake seems to be associated with ulcerative colitis whereas fruit, vegetables and fiber consumption decrease the risk of inflammatory bowel disease [109]. A study on Mediterranean diet and inflammatory markers have revealed that participants closer to the Mediterranean diet have lower levels of CRP, IL-6, fibrinogen and white blood cell counts [110]. By comparison, Lopez-garcia and collaborators [111] revealed high levels of CRP and other inflammatory molecules among people which diet was characterized by red and processed meat, sweets, desserts, French fries and refined grains. So the Mediterranean diet might be effective in reducing the prevalence of metabolic syndrome and associated pro-inflammatory status. In addition, it seems to be associated with increased survival among older people [112].
In modern diets, there are few sources of omega-3 fatty acids, mainly the fat of cold water fish such as salmon, sardines, herring, mackerel, black cod, and bluefish. Specifically, there are two critical omega-3 fatty acids, (eicosapentaenoic acid and docosahexaenoic acid), that the body needs. By contrast, sources of omega- 6 fatty acids are numerous in modern diets. They are found in seeds and nuts, and the oils extracted from them. Refined vegetable oils, such as soy oil, are used in most of the snack foods, cookies, crackers, and sweets in the American diet as well as in fast food. The body also constructs mediators from omega 6 fatty acids. In general, those derived from the two classes of essential fatty acids have opposite effects. Those from omega- 6 fatty acids tend to increase inflammation, blood clotting, and cell proliferation, while those from omega-3 fatty acids decrease those functions. Both families must be in balance to maintain optimum health [113-115].

Finally, a correct dietary intake (sometimes supplemented by minerals or vitamins) in the elderly should be considered as a fundamental factor necessary to improve the health status of the immune system. Actually, it was shown that the dietary supplementation with the recommended daily intakes of zinc for 1 or 2 months decreases the incidence of infections and increases the rate of survival to further infections in elderly people [116].

In the last years, because calorie restriction has been shown to increase maximum life span in several species (not yet in humans), there has been increasing interest in the potential therapeutic use of calorie restriction as a strategy to decrease pro-inflammatory molecules and or increase anti-inflammatory regulators. To this regard, calorie restriction has been demonstrated to down-regulate inflammatory genes and decrease blood inflammatory markers [117]. However, there is no evidence that low calorie intake in the elderly is associated with longevity; in fact a moderate overweight in clinics is the best prognosis for a good outcome of disease in old subjects [118], whereas middle aged individuals (35-65 years) are heavily affected by overweight.

Longevity results from the combination of environment, genetic, epigenetic and stochastic components [119], therefore it is possible to envisage interventions from the environment that can help in retarding the ageing process [120]. To this end, the use of vitamins, minerals and phytochemicals (polyphenols and carotenoids) could be considered, as the major dietary antioxidants. Evidence of epidemiological associations between vitamins and disease have been found for nine vitamins. In observational studies, people with a high intake of antioxidant vitamins by regular diet or as food supplements generally have a lower risk of major chronic disease, such as myocardial infarction or stroke, than people who are low consumers of antioxidant vitamins $[119,120]$. Vitamin D is associated with a decreased occurrence of fractures when taken with calcium. It is known that the immune system contributes to the development of osteoporosis and a possible mechanism is through the chronic up-regulation of pro-inflammatory cytokines which is superimposed with the effects of vitamin D and hormones such as estrogens [121]. Thus, supplementation with vitamin D could have a more general effect on immunosenescence, besides the specific effect on bone metabolism. In addition, new evidences in animal model suggest that vitamin D3 acts as an anti-inflammatory agent, thus being useful for different age-associated diseases, such as AD [122]. Zinc, betacarotene, and vitamin E appear to slow the progression of macular degeneration, but do not reduce its incidence. Vitamin E and lycopene may decrease the risk of prostate cancer [122]. In other randomized controlled trials, the apparent beneficial results of a high intake of antioxidant vitamins seen in observational studies have not been confirmed. However, there is increasing concern from these trials that pharmacological supplementation of vitamins may be associated with a higher mortality risk [123]. On the whole, the role of diet on oxidative stress biomarkers remains unclear and represents a potentially fruitful area for further research in the health area [124]. 
In addition to vitamins and mineral micronutrients, other food components endowed with pharmacological properties can have a potential effect on health and longevity. As an example, many studies indicate that curcumin, the yellow pigment from the rhizoma of Curcuma longa, widely used as a spice, is endowed with a variety of biological activities: anti-inflammatory, anti-oxidative and anti-proliferative [125]. Since oxidative stress and inflammation are major determinants of the ageing process, curcumin can have a more general effect that slows down the rate of ageing [126]. The potentialities to use curcumin as a possible pharmaceutical tool to delay the ageing process depend on its capacity to act on many molecular targets with a very broad range of biological actions, as a pleiotropic factor, as well as its effects as xenohormetic agent, since it activates a sort of stress response in mammalian cells. Curcumin can counteract the pro-inflammatory state which is believed to participate in many age-related diseases. In fact, it seems that curcumin directly affects a few major targets, just like radical scavenging and production and the $\mathrm{NF}-\mathrm{\kappa B}$ signaling pathways, which can in turn suppress the pro-inflammatory state involved in the etiology of ageing and age-related diseases [125]. Moreover, resveratrol, a phytochemical contained in many fruits such as black grapes and in red wine, has been shown to influence lifespan in animal models by lowering inflammatory-oxidative status, but further studies are needed to establish its positive role in humans [127].

\subsection{Physical Exercise}

At present it is clear that the most efficient method that has been used to counteract age-related muscle weakness and decrease morbidity and mortality is long term physical exercise [128], although the exact regime which should be used has not yet been defined.

A possible explanation for the positive health benefits of an active lifestyle and the negative health effects of a sedentary lifestyle come from studies by Pedersen and colleagues [67,129]. Indeed, they demonstrated that exercise-deprivation induced a cluster of physiological abnormalities, similar to metabolic syndrome (such as insulin resistance, impaired glucose uptake and hyperlipidemia). Moreover, exercise also significantly alters muscle gene expression [130]. Thus, it has been proposed that active muscle might secrete one or more factors such as myokines that mediate important changes in gene expression. One of such factors could be IL-6, despite its well known role in the pro-inflammatory pathways. Muscle contraction directly stimulates release of IL-6, which in turn stimulates sequential release of IL-1ra and IL-10, and trained muscle (i.e., muscle with low glycogen content) releases more IL-6 than untrained muscle [130,131]. Although IL-6 mediates some of the physiological effects of exercise, other factors are likely to play a role in this process, such as TNF- $\alpha$, IL-18 and/or brain-derived neurotrophic factors, thus suggesting that skeletal muscle and specifically physical exercise could be considered as mediators to counteract inflamm-ageing at systemic level [132]. Indeed, it is widely recognized that regular, moderate exercise reduced the risk of infection compared with a sedentary lifestyle, whereas prolonged, heavy intensity exercise increased infection risk; the so called "J shaped model" [133]. Recent epidemiological studies indicate that individuals who maintain a physically active lifestyle show an improved glucose metabolism [134].

Physical training has beneficial effects on body weight, on serum lipid levels, on psychosocial stress, on high blood pressure, on insulin resistance and type 2 diabetes. Physical exercise has also anti-inflammatory effects counteracting atherogenesis, angiogenesis and thrombosis. Moreover, physical exercise increases protein synthesis and turnover, increases satellite cell number, stimulates appetite, increases hormone levels including IGF-1 which mediates many positive effects in combating muscle weakness $[135,136]$. To this regard, supplemental mIGF-1 creates a qualitatively different microenvironment for sustaining more efficient muscle regeneration and repair [137].

\section{CONCLUSIONS AND PERSPECTIVES}

The low-grade inflammatory process that occurs with age, "inflamm-ageing", does not have a unique origin, but it could be considered as the result of the contribution of many different factors and molecules, as simplified in Fig. (1). The first type of effect is organ- restricted. This is the case of brain in which dementia (or AD) may develop, or the case of liver with hepatitis or cirrhosis, or the case of muscle with sarcopenia, amongst others. The second type of effect is at systemic level, with the onset and progression of age-related pathologies such as cardiovascular diseases and cancer, which are the main causes of death in the industrialised countries. The site-restricted inflammation could become systemic as a consequence of long lasting release of inflammatory mediators in presence of favouring genetics/epigenetics variants [2,7]. In this contest, only anti-inflammatory strategies may be useful to face this biological mechanism underpinning the major age-related diseases [138].

Age-related changes at hormonal level are crucial for their effects in the inflammatory status and, in particular, cortisol has a profound impact on immune activity with anti-inflamm-ageing effects, as recently reviewed [139]. The interaction of "inflammageing/anti-inflamm-ageing" results in a very complex physiological regulation of different molecules and contributors such as immune system, muscle, liver, adipose tissue and gut microbiota, amongst other. Indeed these organs undergo a different ageing as recently conceptualised [140] and the presence of senescent cells inside organs and tissues may further contribute to the release of other inflammatory mediators. In fact, cell senescence leads to a coordinated secretion of a large number of soluble factors, the so called secretory phenotype, and this occurs in different cell types, following different stressors, that may be associated with the induction of a pro-inflammatory program $[141,142]$. However we did not discuss this point because it is not yet clear if these mediators have a systemic effect or they only act locally in an autocrine-paracrine manner.

Currently, the signalling circuitry and the cross-talk among the various organs, tissues and ecosystems involved are far from being clear. In this composite scenario, we believe that systems biology represents one of the most powerful and comprehensive approach to disentangle the complexity of chronic age-related inflammation, for example by focusing on the role of and the interaction between the immune system, adipose tissue, muscle, brain, liver and gut microbiota in the development, and persistence of inflammation over time [143].

Is "inflamm-ageing" compatible with longevity (100 years of age or more)? The answer is positive and apparently paradoxical, since, even if centenarians have an increased level of inflammatory mediators in comparison to old subjects and they are very frail, they also have high level of anti-inflammatory cytokines together with protective genotypes [3]. Therefore, we think that the most proper approach to tackle and contain age-related inflammation, "inflammageing", is not only to identify the more suitable chemical therapies, but also to better identify the physiological molecules that likely are more present in long lived subjects and influence at the same time different organs of the body with pleiotropic characteristics. Indeed, since inflamm-ageing is a pleiotropic process where many different factors interact, in the same way pleiotropic interventions acting concomitantly on different targets and at different levels are to be preferred and chosen.

\section{ACKNOWLEDGEMENTS}

This work was supported by: the EU Projects "Proteomage" (FP6-518230), "MARK-AGE" (FP7-200880) and "MYO-AGE" (FP7-223576); Roberto and Cornelia Pallotti Legacy for Cancer 


\section{Bloodstream input sites of inflammatory products}

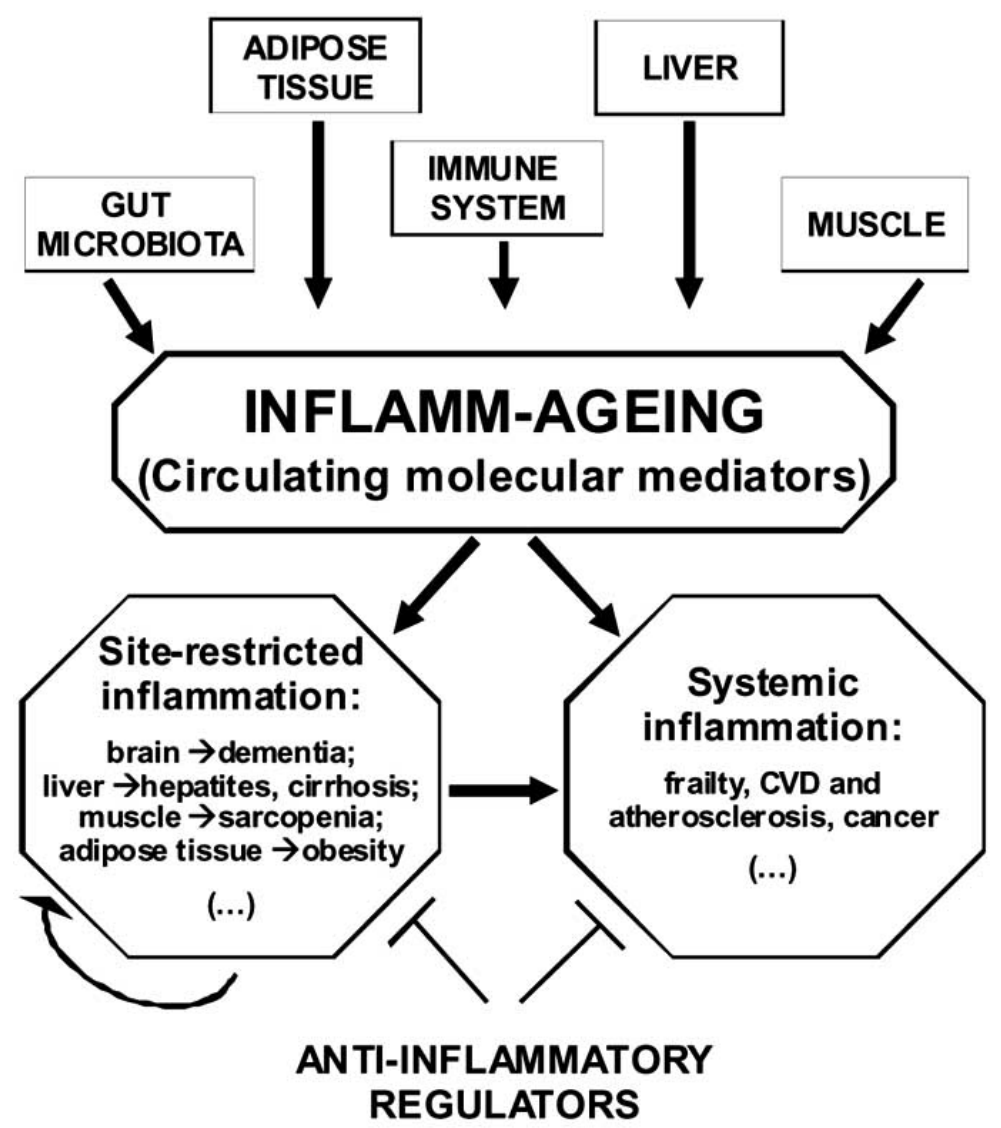

Fig. (1). Inflamm-ageing. Contribution of some tissues (adipose tissue, muscle), organs (brain, liver), immune system and ecosystems (gut microbiota) to inflamm-ageing onset and progression at site-restricted and systemic levels.

Research Grants; University of Bologna "Progetti Strategici" 2006 grant ("Delirio post-operatorio: genetica e fattori di rischio"). Daniele Di Carlo is a PhD student at the Pathobiology $\mathrm{PhD}$ course (directed by Calogero Caruso) of Palermo University and this work is submitted in partial fulfilment of the requirement for his $\mathrm{PhD}$ degree.

\section{ABBREVIATIONS}

$\begin{array}{lll}\mathrm{AD} & = & \text { Alzheimer's Disease } \\ \mathrm{CMV} & = & \text { Cytomegalovirus } \\ \mathrm{COX} & = & \text { Cyclo-oxygenase } \\ \mathrm{IFN} & = & \text { Interferon } \\ \mathrm{IGF} & = & \text { Insulin Growth Factor } \\ \mathrm{IL} & = & \text { Interleukin } \\ \mathrm{IRP} & = & \text { Immune Risk Phenotype } \\ \mathrm{MCP} & = & \text { Monocyte Chemoattractant Protein } \\ \text { mIGF } & = & \text { Muscle restricted IGF } \\ \mathrm{NSAIDs} & = & \text { Non Steroidal Anti-Inflammatory Drugs } \\ \mathrm{TNF} & = & \text { Tumor Necrosis Factor }\end{array}$

\section{REFERENCES}

[1] Vasto S, Scapagnini G, Bulati M, Candore G, Castiglia L, ColonnaRomano CR, et al. Biomarkers of Ageing. Front Biosci 2010; S2: 392-402.
[2] Franceschi C, Bonafe M, Valensin S, Olivieri F, De Luca M, Ottaviani E, et al. Inflamm-ageing. An evolutionary perspective on immunosenescence. Ann NY Acad Sci 2000; 908: 244-54.

[3] Franceschi C, Capri M, Monti DI, Giunta S Olivieri F, Sevini F, et al. Inflamm-ageing and anti-inflammageing: a systemic perspective on ageing and longevity emerged from studies in humans. MAD 2007; 128: 92-105.

[4] Franceschi C. Inflammageing as a major characteristic of old people: can it be prevented or cured? Nutr Rev 2007; 65: S173-6.

[5] Vasto S, Candore G, Balistreri CR, Caruso M, Colonna-Romano G, Grimaldi MP, et al. Inflammatory networks in ageing, age-related diseases and longevity. Mech Ageing Dev 2007; 128: 83-91.

[6] De Martinis M, Franceschi C, Monti D, Ginaldi L. Inflammation markers predicting frailty and mortality in the elderly. Exp Mol Pathol 2006; 80: 219-27.

[7] De Martinis, Franceschi C, Monti D, Ginaldi L. Inflamm-ageing and lifelong antigenic load as major determinants of ageing rate and longevity. FEBS Lett 2005; 579: 2035-9.

[8] Ginaldi L, D Martinis M, Monti D, Franceschi C. Chronic antigenic load and apoptosis in immunosenescence. Trends Immunol 2005; 26: 79-84.

[9] Vasto S, Carruba G, Lio D, Colonna-Romano G, Di Bona D, Candore G, et al. Inflammation, ageing and cancer. Mech Ageing Dev 2009; 130: 40-5.

[10] Sander M, Avlund K, Lauritzen M, Gottlieb T, Halliwell B, Stevnsner T, et al. Ageing-from molecules to populations. Mech Ageing Dev 2008; 129: 614-23.

[11] Capri M, Salvioli S, Sevini F, Valensin S, Celani L, Monti D, et al. The genetics of human longevity. Ann NY Acad Sci 2006; 1067: $252-63$. 
[12] Candore G, Colonna-Romano G, Balistreri CR, Di Carlo D, Grimaldi MP, Listì F, et al. Biology of longevity: role of the innate immune system. Rejuvenation Res 2006; 9: 143-8.

[13] Bonafè M, Barbieri M, Marchegiani F, Olivieri F, Ragno E, Giampieri C, et al. Polymorphic variants of insulin-like growth factor I (IGF-I) receptor and phosphoinositide 3-kinase genes affect IGF-I plasma levels and human longevity: cues for an evolutionarily conserved mechanism of life span control. J Clin Endocrinol Metab 2003; 88: 3299-304.

[14] Franceschi C, Valensin S, Fagnoni F, Barbi C, Bonafè M. Biomarkers of immunosenescence within an evolutionary perspective: the challenge of heterogeneity and the role of antigenic load. Exp Gerontol 1999; 34: 911-21.

[15] Finch CE, Crimmins EM. Inflammatory exposure and historical changes in human life-spans. Science 2004; 305: 1736-9.

[16] Candore G, Balistreri CR, Bulati M, Colonna-Romano G, Di Bona D, Forte GI, et al. Immune-inflammatory responses in successful and unsuccessful ageing. G Gerontol 2009; 57: 145-52.

[17] Larbi A, Franceschi C, Mazzetti D, Solana R, Wiky A, Pawelec G. Ageing of the immune system as a prognostic factor for human longevity. Physiology 2008; 23: 64-74.

[18] Vescovini R, Telera A, Fagnoni FF, Biasini C, Medici MC, Valcavi $\mathrm{P}$, et al. Different contribution of EBV and CMV infections in very long-term carriers to age-related alterations of $\mathrm{CD} 8^{+} \mathrm{T}$ cells. Exp Gerontol 2004; 39: 1233-43.

[19] Sylwester AW, Mitchell BL, Edgar JB, Taormina C, Pelte C, Ruchti $\mathrm{F}$, et al. Broadly targeted human cytomegalovirus-specific $\mathrm{CD}^{+}$and $\mathrm{CD}^{+} \mathrm{T}$ cells dominate the memory compartments of exposed subjects. J Exp Med 2005; 202: 673-85.

[20] Vescovini R, Biasini C, Fagnoni FF, Telera AR, Zanlari L, Pedrazzoni M, et al. Massive load of functional effector $\mathrm{CD} 4^{+}$and $\mathrm{CD}^{+} \mathrm{T}$ cells against cytomegalovirus in very old subjects. $\mathrm{J}$ Immunol 2007; 179: 4283-91.

[21] Schmaltz HN, Fried LP, Xue QL, Walston J, Leng SX, Semba RD. Chronic cytomegalovirus infection and inflammation are associated with prevalent frailty in community-dwelling older women. J Am Geriatr Soc 2005; 53: 747-54.

[22] Koch S, Larbi A, Ozcelik D, Solana R, Gouttefangeas C, Attig S, et al. Cytomegalovirus infection: a driving force in human $\mathrm{T}$ cell immunosenescence. Ann NY Acad Sci 2007; 1114: 23-35.

[23] Pawelec G, Akbar A, Caruso C, Solana R, Grubeck-Loebenstein B, Wikby A. Human immunosenescence: is it infectious? Immunol Rev 2005; 205: 257-68.

[24] Derhovanessian E, Larbi A, Pawelec G. Biomarkers of human immunosenescence: impact of Cytomegalovirus infection. Curr Opin Immunol 2009; 21: 440-5.

[25] Cipriano C, Caruso C, Lio D, Giacconi R, Malavolta M, Muti E, et al. The -308G/A polymorphism of TNF-alpha influences immunological parameters in old subjects affected by infectious diseases. Int J Immunogenet 2005; 32: 13-8.

[26] Bäckhed F, Ley RE, Sonnenburg JL, Peterson DA, Gordon JI. Host-bacterial mutualism in the human intestine. Science 2005; 307: 1915-20.

[27] Gill SR, Pop M, Deboy RT, Eckburg PB, Turnbaugh PJ, Samuel BS, et al. Metagenomic analysis of the human distal gut microbiome. Science 2006; 312: 1355-9.

[28] Ley RE, Peterson DA, Gordon JI. Ecological and evolutionary forces shaping microbial diversity in the human intestine. Cell 2006; 124: 837-48.

[29] Guarner F, Malagelada JR. Gut flora in health and disease. Lancet 2003; 361: 512-9.

[30] Hooper LV, Gordon JI. Commensal host-bacterial relationships in the gut. Science 2001; 292: 1115-8.

[31] Nicholson JK, Holmes E, Wilson ID. Gut microorganisms, mammalian metabolism and personalized health care. Nat Rev Microbiol 2005; 3: 431-8

[32] Ley RE, Bäckhed F, Turnbaugh P, Lozupone CA, Knight RD, Gordon JI. Obesity alters gut microbial ecology. Proc Natl Acad Sci USA 2005; 102: 11070-5.

[33] Gore C, Munro K, Lay C, Bibiloni R, Morris J, Woodcock A, et al. Bifidobacterium pseudocatenulatum is associated with atopic eczema: a nested case-control study investigating the fecal microbiota of infants. J Allergy Clin Immunol 2008; 12: 135-40.

[34] Sokol H, Lepage P, Seksik P, Doré J, Marteau P. Molecular comparison of dominant microbiota associated with injured versus healthy mucosa in ulcerative colitis. Gut 2007; 56: 152-4.
[35] Kinross JM, von Roon AC, Holmes E, Darzi A, Nicholson JK. The human gut microbiome: implications for future health care. Curr Gastroenterol Rep 2008; 10: 396-403.

[36] Othman M, Agüero R, Lin HC. Alterations in intestinal microbial flora and human disease. Curr Opin Gastroenterol 2008; 24: 11-6.

[37] van Tongeren SP, Slaets JP, Harmsen HJ, Welling GW. Fecal microbiota composition and frailty. Appl Environ Microbiol 2005; 71: 6438-42.

[38] Mueller S, Saunier K, Hanisch C, Norin E, Alm L, Midtvedt T, et al. Differences in fecal microbiota in different European study populations in relation to age, gender, and country: a cross-sectional study. Appl Environ Microbiol 2006; 72: 1027-33.

[39] Capri M, Monti D, Salvioli S, Lescai F, Pierini M, Altilia S, et al. Complexity of anti-immunosenescence strategies in humans. Artif Organs 2006; 30: 730-42.

[40] Candore G, Balistreri CR, Colonna-Romano G, Grimaldi MP, Lio $\mathrm{D}$, Listi' F, et al. Immunosenescence and anti-immunosenescence therapies: the case of probiotics. Rejuvenation Res 2008; 11: 42532

[41] Sera Y, LaRue AC, Moussa O, Mehrotra M, Duncan JD, Williams $\mathrm{CR}$, et al. Hematopoietic stem cell origin of adipocytes. Exp Hematol 2009; 37: 1108-20.

[42] Rudin E, Barzilai N. Inflammatory peptides derived from adipose tissue. Immun Ageing 2005; 2: 1.

[43] Semenkovich CF. Insulin resistance and atherosclerosis. J Clin Invest 2006; 116: 1813-22.

[44] Wellen KE, Hotamisligil GS. Obesity-induced inflammatory changes in adipose tissue. J Clin Invest 2003; 112: 1785-8.

[45] Hansson GK. Inflammatory mechanisms in atherosclerosis. J Thromb Haemost 2009; 7 (Suppl 1): 328-31.

[46] Surmi BK, Hasty AH. Macrophage infiltration into adipose tissue: initiation, propagation and remodelling. Future Lipidol 2008; 3 : 545-56.

[47] Lorenzo M, Fernández-Veledo S, Vila-Bedmar R, Garcia-Guerra L, De Alvaro C, Nieto-Vazquez I. Insulin resistance induced by tumor necrosis factor-alpha in myocytes and brown adipocytes. J Anim Sci 2008; 86: E94-104.

[48] Nieto-Vazquez I, Fernández-Veledo S, Krämer DK, Vila-Bedmar R, Garcia-Guerra L, Lorenzo M. Insulin resistance associated to obesity: the link TNF-alpha. Arch Physiol Biochem 2008; 114: 183-

[49] Fernández-Veledo S, Nieto-Vazquez I, Vila-Bedmar R, GarciaGuerra L, Alonso-Chamorro M, Lorenzo M. Molecular mechanisms involved in obesity-associated insulin resistance: therapeutical approach. Arch Physiol Biochem 2009; 115: 227-39.

[50] Uysal KT, Wiesbrock SM, Marino MW, Hotamisligil GS Protection from obesity-induced insulin resistance in mice lacking TNF-alpha function. Nature 1997; 389: 610-4.

[51] Melton $3^{\text {rd }}$ LJ, Khosla S, Crowson CS, O'Connor MK, O'Fallon WM, Riggs BL. Epidemiology of sarcopenia. J Am Geriatr Soc 2000; 48: 625-30.

[52] Licastro F, Candore G, Lio D, Porcellini E, Colonna-Romano G, Franceschi $\mathrm{C}$, et al. Innate immunity and inflammation in ageing: a key for understanding age-related diseases. Immun Ageing 2005; 2 :

[53] Griffiths RD. Muscle mass, survival, and the elderly ICU patient. Nutrition 1996; 12: 456-8.

[54] Poehlman ET, Toth MJ, Fonong T. Exercise, substrate utilization and energy requirements in the elderly. Int J Obesity Relat Metab Disord 1995; 19: S93-6.

[55] Cesari M, Penninx BW, Pahor M, Lauretani F, Corsi AM, Williams $\mathrm{RG}$, et al. Inflammatory markers and physical performance in older persons: the InCHIANTI study. J Gerontol A Biol Sci Med Sci 2004; 59: 242-8

[56] Cappola AR, Xue QL, Ferrucci L, Guralnik JM, Volpato S, Fried LP. Insulin-like growth factor I and interleukin-6 contribute synergistically to disability and mortality in older women. J Clin Endocrinol Metab 2003; 88: 2019-25.

[57] Schaap LA, Pluijm SM, Deeg DJ, Visser M. Inflammatory markers and loss of muscle mass (sarcopenia) and strength. Am J Med 2006; 119: 526. e9-17.

[58] Roubenoff R. Catabolism of aging: is it an inflammatory process? Curr Opin Clin Nutr Metab Care 2003; 6: 295-9.

[59] Visser M, Pahor M, Taaffe DR, Goodpaster BH, Simonsick EM, Newman AB, et al. Relationship of interleukin-6 and tumor necrosis factor-alpha with muscle mass and muscle strength in 
elderly men and women: the health ABC study. J Gerontol A Biol Sci Med Sci 2002; 57: M326-32.

[60] Ferrucci L, Penninx BW, Volpato S, Harris TB, Bandeen-Roche K, Balfour $\mathrm{J}$, et al. Change in muscle strength explains accelerated decline of physical function in older women with high interleukin-6 serum levels. J Am Geriatr Soc 2002; 50: 1947-54.

[61] Baumgartner RN, Waters DL, Gallagher D, Morley JE, Garry PJ. Predictors of skeletal muscle mass in elderly men and women. Mech Ageing Dev 1999; 107:123-36.

[62] Krabbe KS, Pedersen M, Bruunsgaard H. Inflammatory mediators in the elderly. Exp Gerontol 2004; 39: 687-99.

[63] Lelbach A, Scharf JG, Ramadori G. Regulation of insulin-like growth factor-I and of insulin-like growth factor binding protein-1, -3 and -4 in cocultures of rat hepatocytes and Kupffer cells by interleukin-6. J Hepatol 2001; 35: 558-67.

[64] Barbieri M, Ferrucci L, Ragno E, Corsi A, Bandinelli S, Bonafe M, et al. Chronic inflammation and the effect of IGF-I on muscle strength and power in older persons. Am J Physiol Endocrinol Metab 2003; 284: E481-7.

[65] Pelosi L, Giacinti C, Nardis C, Borsellino G, Rizzuto E, Nicoletti C, et al. Local expression of IGF-1 accelerates muscle regeneration by rapidly modulating inflammatory cytokines and chemokines. FASEB J 2007; 21: 1393-402.

[66] Petersen AM, Pedersen BK. The role of IL-6 in mediating the antiinflammatory effects of exercise. Physiol Pharmacol 2006; 57: 4351.

[67] Pedersen BK. The anti-inflammatory effect of exercise: its role in diabetes and cardiovascular disease control. Essays Biochem 2006; 42: 105-17.

[68] Pedersen BK, Fischer CP. Physiological roles of muscle-derived interleukin-6 in response to exercise. Curr Opin Clin Nutr Metab Care 2007; 10: 265-71.

[69] Pedersen BK. IL-6 signalling in exercise and disease. Biochem Soc Trans 2007; 35: 1295-7.

[70] Eikelenboom P, Veerhuis R, Scheper W, Rozemuller AJ, van Gool WA, Hoozemans JJ. The significance of neuroinflammation in understanding Alzheimer's disease. J Neural Transm 2006; 113: 1685-95.

[71] Vasto S, Candore G, Listì F, Balistreri CR, Colonna-Romano G, Malavolta M, et al. Inflammation, genes and zinc in Alzheimer's disease. Brain Res Rev 2008; 58: 96-105.

[72] Balistreri CR, Grimaldi MP, Chiappelli M, Licastro F, Castiglia L, Listì F, et al. Association between the polymorphisms of TLR4 and CD14 genes and Alzheimer's disease. Curr Pharm Des 2008; 14: 2672-7.

[73] Di Bona D, Plaia A, Vasto S, Cavallone L, Lescai F, Franceschi C, et al. Association between the interleukin-1beta polymorphisms and Alzheimer's disease: a systematic review and meta-analysis. Brain Res Rev 2008; 59: 155-63.

[74] Vasto S, Candore G, Duro G, Lio D, Grimaldi MP, Caruso C. Alzheimer's disease and genetics of inflammation: a pharmacogenomic vision. Pharmacogenomics 2007; 8: 1735-45.

[75] Listì F, Candore G, Balistreri CR, Grimaldi MP, Orlando V, Vasto $\mathrm{S}$, et al. Association between the HLA-A2 allele and Alzheimer disease. Rejuvenation Res 2006; 9: 99-101.

[76] Ruan L, Kang Z, Pei G, Le Y. Amyloid deposition and inflammation in Appswe/Ps1de9 mouse model of Alzheimer's disease. Curr Alzheimer Res 2009; 6: 531-40.

[77] Sersté T, Bourgeois N. Ageing and the liver. Acta Gastroenterol Belg 2006; 69: 296-8.

[78] Anantharaju A, Feller A, Chedid A. Aging Liver. Gerontology 2002; 48: 343-53.

[79] Schmucker DL. Liver function and phase I drug metabolism in the elderly: a paradox. Drugs Ageing 2001; 18: 837-51.

[80] Cescon M, Grazi GL, Ercolani G. Long-term survival of recipients of liver grafts from donors older than 80 years: is it achievable? Liver Transp 2003; 9: 1174-80.

[81] Arii S, Imamura M. Physiological role of sinusoidal endothelial cells and Kupffer cells and their implication in the pathogenesis of liver injury. J Hepatobiliary Pancreatic Surg 2000; 7: 40-8.

[82] Hilmer SN, Cogger VC, Le Couteur DG. Basal activity of Kupffer cells increases with old age. J Gerontol A Biol Sci Med Sci 2007; 62: 973-8.

[83] Norman K, Pirlich M. Gastrointestinal tract in liver disease: which organ is sick? Curr Opin Clin Nutr Metab Care 2008; 11: 613-9.
[84] Greter M, Hofmann J, Becher B. Neo-lymphoid aggregates in the adult liver can initiate potent cell-mediated immunity. PLoS Biol 2009; 7: e1000109.

[85] Armstrong BG, Mangtani P, Fletcher A, Kovats S, McMichael A, Pattenden $\mathrm{S}$, et al. Effect of influenza vaccination on excess deaths occurring during periods of high circulation of influenza: cohort study in elderly people. BMJ 2004; 329: 660-4.

[86] Hedlund J, Christenson B, Lundbergh P, Ortqvist A. Effects of a large-scale intervention with influenza and 23-valent pneumococcal vaccines in elderly people: a 1-year follow-up. Vaccine 2003; 21 : 3906-11.

[87] Goodwin K, Viboud C, Simonsen L. Antibody response to influenza vaccination in the elderly: a quantitative review. Vaccine 2006; 24: 1159-69.

[88] Jefferson T, Rivetti D, Rivetti A, Rudin M, Di Pietrantoni C, Demicheli V. Efficacy and effectiveness of influenza vaccines in elderly people: a systematic review. Lancet 2005; 366: 1165-74.

[89] Trzonkowski P, Mysliwska J, Szmit E, Wieckiewicz J, Lukaszuk K, Brydak LB, et al. Association between cytomegalovirus infection, enhanced proinflammatory response and low level of antihemagglutinins during the anti-influenza vaccination an impact of immunosenescence. Vaccine 2003; 21: 3826-36.

[90] Riddell SR, Watanabe KS, Goodrich JM, Li CR, Agha ME, Greenberg PD. Restoration of viral immunity in immunodeficient humans by the adoptive transfer of T cell clones. Science 1992; 257: 238-41.

[91] Walter EA, Greenberg PD, Gilbert MJ, Finch RJ, Watanabe KS, Thomas ED, et al. Reconstitution of cellular immunity against Cytomegalovirus in recipients of allogeneic bone marrow by transfer of T-cell clones from the donor. N Engl J Med 1995; 333: 1038-44.

[92] Andre-Schmutz I, Dal Cortivo L, Hamel Y, Cavazzana-Calvo M. Gene transfer for activation of CMV specific $\mathrm{T}$ cells. Hum Immunol 2004; 65: 565-70.

[93] Pawelec G, Akbar A, Caruso C, Solana R, Grubeck-Loebenstein B, Wikby A. Human immunosenescence: Is it infectious? Immunol Rev 2005; 205: 257-68.

[94] Giorno L, Drioli E. Biocatalytic membrane reactors: applications and perspectives. Trends Biotechnol 2000; 18: 339-49.

[95] Yonekawa M, Kawamura A, Komai T, Agishi T, Adachi M. Extracorporeal granulocytapheresis for cancer and rheumatoid arthritis. Transfus Sci 1996; 17: 463-72.

[96] Ishizuka T, Kawata T, Shimizu Y, Utsugi M, Endou K, Hisada T, et al. Safety and efficacy of extracorporeal granulocyte and monocyte adsorption apheresis in patients with severe persistent bronchial asthma. Inflammation 2005; 29: 9-16.

[97] Silverstein AM. Labeled antigens and antibodies: the evolution of magic markers and magic bullets. Nat Immunol 2004; 5: 1211-7.

[98] Berzins SP, Uldrich AP, Sutherland JS, Gill J, Miller JF, Godfrey DI, et al. Thymic regeneration: teaching an old immune system new tricks. Trends Mol Med 2002; 8: 469-76.

[99] Muraro PA, Douek DC. Renewing the T cell repertoire to arrest autoimmune aggression. Trends Immunol 2006; 27: 61-7.

[100] Voehringer D, Liang HE, Locksley RM. Homeostasis and effector function of lymphopenia-induced "memory-like" $\mathrm{T}$ cells in constitutively T cell-depleted mice. J Immunol 2008; 180: 4742-53.

[101] Watson J, McKay DM. The immunophysiological impact of bacterial CpG DNA on the gut. Clin Chim Acta 2006; 364: 1-11.

[102] Sartor RB. Probiotic therapy of intestinal inflammation and infections. Curr Opin Gastroenterol 2005; 21:44-50.

[103] Lammers KM, Brigidi P, Vitali B, Gionchetti P, Rizzello F, Caramelli E, et al. Immunomodulatory effects of probiotic bacteria DNA: IL-1 and IL-10 response in human peripheral blood mononuclear cells. FEMS Immunol Med Microbiol 2003; 38: 16572.

[104] Shanahan F. Physiological basis for novel drug therapies used to treat the inflammatory bowel diseases I. Pathophysiological basis and prospects for probiotic therapy in inflammatory bowel disease. Am J Physiol Gastrointest Liver Physiol 2005; 288: G417-21.

[105] Martin BK, Szekely C, Brandt J, Piantadosi S, Breitner JC, Craft S, et al. Cognitive function over time in the Alzheimer's Disease Antiinflammatory Prevention Trial (ADAPT): results of a and celecoxib. Arch Neurol 2008; 65: 896-905.

[106] Bregman N, Karni A, Korczyn AD. Can treatment with nonsteroidal anti-inflammatory drugs protect from dementia? Arch Neurol 2009; 66: 539-540. 
[107] Caruso C, Balistreri CR, Candore G, Carruba G, Colonna-Romano $\mathrm{G}$, Di Bona D, et al. Polymorphisms of pro-inflammatory genes and prostate cancer risk: a pharmacogenomic approach. Cancer Immunol Immunother 2009; 58: 1919-33.

[108] Choi HK. Diet, alcohol, and gout: how do we advise patients given recent developments? Curr Rheumatol Rep 2005; 7: 220-6.

[109] Danese S, Sans M, Fiocchi C. Inflammatory bowel disease: the role of environmental factors. Autoimmun Rev 2004; 3: 394-400.

[110] Chrysohoou C, Panagiotakos DB, Pitsavos C, Das UN, Stefanadis C. Adherence to the Mediterranean diet attenuates inflammation and coagulation process in healthy adults: The ATTICA Study. J Am Coll Cardiol 2004; 44: 152-8.

[111] Lopez-Garcia E, Schulze MB, Fung TT, Meigs JB, Rifai N, Manson JE, et al. Major dietary patterns are related to plasma concentrations of markers of inflammation and endothelial dysfunction. Am J Clin Nutr 2004; 80: 1029-35.

[112] Trichopoulou A, Orfanos P, Norat T, Bueno-de-Mesquita B, Ocké MC, Peeters PH, et al. Modified Mediterranean diet and survival: EPIC-elderly prospective cohort study. BMJ 2005; 330: 991.

[113] Siddiqui RA, Shaikh SR, Sech LA, Yount HR, Stillwell W, Zaloga GP. Omega 3-fatty acids: health benefits and cellular mechanisms of action. Mini Rev Med Chem 2004; 4: 859-71.

[114] Bourre JM. Where to find omega-3 fatty acids and how feeding animals with diet enriched in omega-3 fatty acids to increase nutritional value of derived products for human: what is actually useful ? J Nutr Health Aging 2009; 9: 232-42.

[115] Margioris AN. Fatty acids and postprandial inflammation. Curr Opin Clin Nutr Metab Care 2009; 12: 129-37.

[116] Mocchegiani E, Muzzioli M, Giacconi R. Zinc and immunoresistance to infection in ageing: new biological tools. Trends Pharmacol Sci 2000; 21: 205-8

[117] Fontana L, Klein S. Aging, adiposity, and calorie restriction. JAMA 2007; 297: 986-94.

[118] Rössner S. Obesity in the elderly--a future matter of concern? Obes Rev 2001; 2: 183-8.

[119] Franceschi C, Motta L, Motta M, Malaguarnera M, Capri M, Vasto $\mathrm{S}$, et al. The extreme longevity: the state of the art in Italy. Exp Gerontol 2008; 43: 45-52.

[120] Caruso C, Jirillo E. Drug targets in ageing and age-associated diseases. Curr Pharm Des 2008; 14: 2635-6.

[121] Clowes JA, Riggs BL, Khosla S. The role of the immune system in the pathophysiology of osteoporosis. Immunol Rev 2005; 208:20727.

[122] Moore ME, Piazza A, McCartney Y, Lynch MA. Evidence that vitamin D3 reverses age-related inflammatory changes in the rat hippocampus. Biochem Soc Trans 2005; 33: 573-7.

[123] Thomas DR. Vitamins in ageing, health, and longevity. Clin Interv Ageing 2006; 1: 81-91.

[124] Barbosa KB, Bressan J, Zulet MA, Martínez Hernández JA. Influence of dietary intake on plasma biomarkers of oxidative stress in humans. An Sist Sanit Navar 2008; 31: 259-80.

[125] Salvioli S, Sikora E, Cooper EL, Franceschi C. Curcumin in cell death processes: a challenge for CAM of age-related pathologies. Evid Based Complement Alternat Med 2007; 4: 181-90.

[126] Sikora E, Bielak-Żmijewska A, Mosieniak G, Piwocka K. The promise of slow down ageing may come from curcumin. Curr Pharm Des 2010; 16: 884-892.
[127] Knutson MD, Leeuwenburgh C. Resveratrol and novel potent activators of SIRT1: effects on aging and age-related diseases. Nutr Rev 2008; 66: 591-6.

[128] Paffenbarger RS Jr, Kampert JB, Lee IM, Hyde RT, Leung RW, Wing AL. Changes in physical activity and other lifeway patterns influences longevity. Med Sci Sports Exerc 1994; 26: 857-65.

[129] Pedersen BK. The diseasome of physical inactivity- and the role of myokines in muscle-fat cross talk. J Physiol 2009; doi:10.1113/ jphysiol.2009.179515.

[130] Buford TW, Cooke MB, Shelmadine BD, Hudson GM, Redd L, Willoughby DS. Effects of eccentric treadmill exercise on inflammatory gene expression in human skeletal muscle. Appl Physiol Nutr Metab 2009; 34: 745-53.

[131] Steensberg A, Fischer CP, Keller C, Moller K, Pedersen BK. IL-6 enhances plasma IL-1ra, IL-10, and cortisol in humans. Am J Physiol Endocrinol Metab 2003; 285: E433-E437.

[132] Mathur N, Pedersen BK. Exercise as a mean to control low-grade systemic inflammation. Mediators Inflamm 2008; 2008: 109502.

[133] Nieman DC. Exercise, infection, and immunity. Int J Sports Med 1994; 15: S131-S41.

[134] Wang Y, Simar D, Fiatarone SMA. Adaptations to exercise training within skeletal muscle in adults with type 2 diabetes or impaired glucose tolerance: a systematic review. Diabetes Metab Res Rev 2009; 25: 13-40.

[135] Colbert LH, Visser M, Simonsick EM, Tracy RP, Newman AB, Kritchevsky SB, et al. Physical activity, exercise, and inflammatory markers in older adults: findings from the Health, Aging and Body Composition Study. J Am Geriatr Soc 2004; 52: 1098-104.

[136] Krishan K, Dhoot GK. Changes in some troponin and insulin-like growth factor messenger ribonucleic acids in regenerating and denervated skeletal muscles. J Muscle Res Cell Motil 1996; 17 513-21.

[137] Musarò A, McCullagh K, Paul A, Houghton L, Dobrowolny G, Molinaro M, et al. Localized Igf-1 transgene expression sustains hypertrophy and regeneration in senescent skeletal muscle. Nat Genet 2001; 27: 195-200.

[138] Chung HY, Cesari M, Anton S, Marzetti E, Giovannini S, Seo AY, et al. Molecular inflammation: underpinnings of aging and agerelated diseases. Ageing Res Rev 2009; 8: 18-30.

[139] Giunta S. Exploring the complex relations between inflammation and aging (inflamm-aging): anti-inflamm-aging remodelling of inflamm- aging, from robustness to frailty. Inflamm Res 2008; 57 : 558-63

[140] Cevenini E, Invidia L, Lescai F, Salvioli S, Tieri P, Castellani G, et al. Human models of aging and longevity. Expert Opin Biol Ther. 2008; 8: 1393-405

[141] Evan GI, d'Adda di Fagagna F. Cellular senescence: hot or what? Curr Opin Genet Dev 2009; 19: 25-3.

[142] Campisi J. Senescent cells, tumor suppression, and organismal aging: good citizens, bad neighbors. Cell 2005; 120: 513-22.

[143] Cevenini E, Bellavista E, Tieri P, Castellani G, Lescai F, Francesconi M, et al. Systems Biology and Longevity: an emerging approach to identify innovative anti-aging targets and strategies. Curr Pharm Des 2010; 16: 802-813. 